\title{
Rich? Inquisitive? Confused? Book a safari to the "wild side" of private boutique medicine
}

$\mathrm{M}$ ost people wouldn't think of Alberta as an exotic safari destination. But for customers who have the money, time and a certain inquisitiveness around health care, there is lots to see and do.

I'm assured by the brochures that your chances of being gored by a wildebeest or eaten by a hyena are fairly small. However, the chances of getting the health scare of a lifetime are likely greatly increased if you visit one of Alberta's boutique health care clinics because the tests they conduct are intensely inclusive, detailed and comprehensive.

A just-published report on the controversy around a new private healthcare clinic in Edmonton brought this possibility clearly into focus. On one side, the critics are damning this new private clinic as an elitist health boutique, whose owners are clearly flouting the Canada Health Act and, in the process, threatening to destroy all that is true and Canadian. On the other side, the owners, defending their entrepreneurial élan, say all they want to do is serve those eager to partake of their spa-like, world-leading, preventive health care services

If this isn't the archetypal Canadian health care public-private feud, I don't know what is, but it does elicit a few questions. Who can shell out $\$ 3000$ to $\$ 4000$ per year for this kind of safari? Is it only for the really sick and wealthy? Not at all. These well-heeled clients generally aren't sick nor are they buying access to advanced treatments for rare, life-threatening illnesses, or seeking out cures for cancers or cardiac disease. They're purchasing the most mundane-sounding of medical excursions: medical screening of the fishing-expedition type, not the diagnostic type

Today's private-boutique screening is so exotic that you rarely see it in the public system - such as scans so sen-

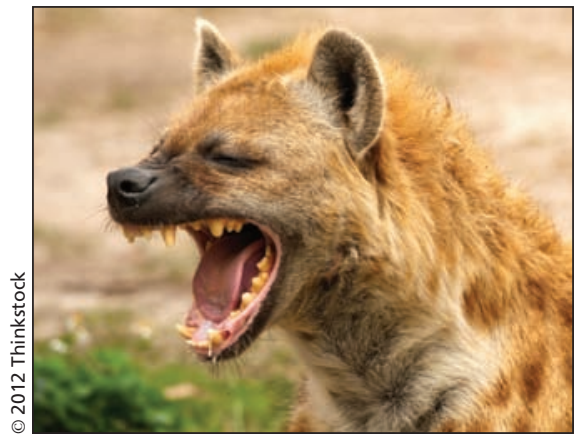

sitive you'll spend the next year getting biopsies for things they find inside your body that would never hurt you.

It's not just Alberta that has such thorough screening boutiques, one company, with offices in several provices, also offers a "comprehensive Executive Health \& Lifestyle Assessment," which includes "a range of procedures to evaluate cancer and cardiac risk, assess vision, hearing and lung functions, and evaluate lifestyle factors such as exercise, diet, stress and smoking."

At the Alberta clinic, an annual fee gets you an exclusive, four-hour checkup from a health care team, complete with up-close-and-personal attention from a doctor, a nurse-lifestyle coach, an exercise specialist and a dietician. In fact, the examination is so lengthy and thorough, that while you won't leave the clinic any sicker, you will likely leave feeling more worried than when you went in. As the saying goes, those who think they're well just haven't had enough tests.

The private clinic staff and their precision-guided scanners will look closely to see if there is anything wrong with your organs and put you through the mill to test for twelve types of cancer. You might also be advised to purchase a computed tomography scan or magnetic resonance imaging at an affiliated clinic or submit some saliva to obtain your genetic profile from a personalized genetic-screening company. All this can be arranged. You'd never get this level of "service" in the public system.

Now, why is that? Much of the screening offered in these kinds of boutique clinics is, in the public system, available in only very limited supply for a very good reason: screening is fraught with the dangers of overdiagnosis. That is, there is a much higher chance they'll find things that won't hurt you than something that will. Then more tests and procedures follow.

Do you need a team of health professionals slapping you around with their opinion of your lifestyle choices? Do you really need more scans, biopsies and screening to deal with the bumps, moles and scabs they find? Is it worth trading the peace of mind you seek for a fresh helping of health anxiety?

While the critics decry the financial barriers and say such clinics are leading to two-tier healthcare, I worry about technology biting back. Regardless of the reassurances in the brochures, when you embark on an expensive, high-tech health-hunting expedition and fall victim to the unforeseen, who is going to pay to fix you after that? The already overwhelmed public system.

A fool and their preventive health care dollars are soon parted. There will always be those wanting to buy excursions to exotic locations - even to Alberta - but the question we need to ask is this: Why should the rest of us have to foot the bill?

\section{Alan Cassels MPA \\ Drug Policy Researcher \\ University of Victoria \\ Victoria, BC}

Alan Cassels' book, Seeking Sickness: Medical Screening and the Misguided Hunt for Disease (Greystone Books) was published in April.

CMAJ 2012. DOI:10.1503/cmaj.120336 